\title{
Normotensive vs Hypertensive: Blood Pressure Response During Incremental Exercise
}

\author{
Daniel Jaffe*, Jennifer Hewit and Todd Crowder \\ Department of Physical Education, United States Military Academy, USA \\ *Corresponding author: Daniel Jaffe, Department of Physical Education, United States Military Academy, West Point, NY, USA
}

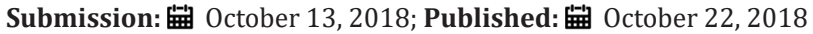

\section{Opinion}

At rest, heart rate is maintained at approximately $60-100$ beats per minute by innervation of the parasympathetic nervous system [1]. Elevated parasympathetic activity via constant stimulation of the Vagus nerve will yield a significant decline in heart rate, known clinically as bradycardia [2,3]. The right branch of the Vagus nerve inhibits the SA node, or the cardiac pacemaker, while the left branch of the Vagus nerve inhibits the AV node [2]. While performing exercise, the heart will conduct the same functions as it would at rest, but at a much more accelerated rate. Given that the cardiovascular system is a closed system, there exists only a set volume of blood in pulmonic and systemic circulation of approximately 5 Liters in the reference person [1]. To accommodate increased metabolic activity, cardiac output, defined as the product of heart rate and stroke volume, must be increased to match the metabolic demands of the activity i.e. the finite quantity of blood must be circulated at a much greater rate than it would be at rest $[1,2]$. Heart rate increases observed upon initiation of physical activity are attributed to a withdrawal of vagal tone, or a reduction in parasympathetic influence over the myocardium [1]. Once the heart rate reaches approximately 100 beats per minute, or the base sinus rhythm set by the sinoatrial node, sympathetic activation takes control and elevates heart rate up to 250 beats per minute, depending upon exercise intensity [1,2]. Heart rate can be calculated using ECG tracings by identifying the duration of the R-R interval [4].

In addition to a significant increase in rate, sympathetic activity also dramatically increases the force of contraction of the ventricles, resulting in dramatic increases in blood pressure and blood flow velocity [5,6]. For example, Saltin et al. [5] have revealed through Doppler analysis that quantity and rate of blood flow through the femoral artery can increase more than 20 -fold when going from a resting to exercising state, increasing from $0.3 \mathrm{~L}$ per minute, to a flow exceeding 6-10L per minute, respectively. In essence, this example has demonstrated the need to dramatically increase the rate and quantity of blood flowing through the heart during exercise relative to the quantities observed at rest. A broad range of factors found within the vasculature itself can greatly influence vasomotion both at rest and during exercise [6,7]. As exercise intensity increases, metabolite production and accumulation will initiate vasodilation. These vasodilator substances include adenosine, potassium, and nitric oxide [2]. With a decrease in peripheral vasoconstriction to the metabolically active tissues and the shunting of blood from the inactive tissue, including the inactive muscles, kidneys, and splanchnic region, adequate diffusion and exchange takes place between the capillary beds and the tissues to maintain activity [2,7].

During exercise, the standard systolic blood pressure (SBP) response to an average increase of $2 \mathrm{mmHg}$ per metabolic equivalent (MET) of exercise intensity, with a possible plateau once exercise peak has been reached, and cessation of exercise when SBP exceeds $250 \mathrm{mmHg}[8,9]$. On the other hand, diastolic blood pressure (DBP) demonstrates little to no observable change during exercise, with an exercise endpoint identified as any DBP greater than $115 \mathrm{mmHg}$ $[8,9]$. When training individuals with diagnosed hypertension, it is imperative to be aware of what types of medications they may be taking. When taking vasodilators, specifically calcium channel blockers, angiotensin-converting enzyme inhibitors, and $\alpha$ - and $\beta$-blockers, blood pressure responses will be variably attenuated and difficult to predict [8]. Hypertensives also tend to exhibit an unusual rise in DBP, due to their inability to reduce total peripheral resistance (TPR). This dysfunction may be attributable to endothelial dysfunction, or a reduced lumen-to-wall thickness [10].

\section{References}

1. Wilmore JH, Costill DL, Kenney WL (2008) Physiology of sport and exercise $\left(4^{\text {th }}\right.$ edn), Human Kinetics Publishers, Inc, Champaign, IL, USA.

2. Astrand PO, Rodahl K, Dahl HA, Stromme SB (2003) Textbook of work physiology: physiological bases of exercise. ( $4^{\text {th }}$ edn), Human Kinetics Publishers, Inc, Champaign, IL, USA.

3. Wunderly K, Yousef Z, Boddy A, Weatherwax KJ, Lavan B, et al. (2018) Using reconditioned pacemakers to treat bradycardia in Africa. Nature Reviews: Cardiology.

4. Goldberger AL (2006) Clinical Electrocardiography. Mosby, Philadelphia, PA, USA.

5. Saltin B, Radegran G, Koskolou MD, Roach RC (1998) Skeletal muscle blood flow in humans and its regulation during exercise. Acta Physiologica Scandinavica 162 (3): 421-426 
6. Van der Kleij LA, Petersen ET, Siebner HR, Hendrikse J, Frederiksen KS et al. (2018) The effect of physical exercise on cerebral blood flow in Alzheimer's disease. Neuroimage Clin 20: 650-654.

7. Westhoff J, Weismuller K, Koch C, Mann V, Weigand MA, et al. (2018) Vasomotion of mice mesenteric arteries during low oxygen levels. Eur J Med Res 23(1): 38.

8. American College of Sports Medicine (2018). Guidelines for exercise testing and prescription. (10 $0^{\text {th }}$ edn), Williams \& Wilkins, Philadelphia, USA.
9. Grafe K, Bendick P, Burr M, Boura J, Franklin BA (2018) Effects of resistance training on vascular and hemodynamic responses in patients with coronary artery disease. Res Q Exerc Sport 9: 1-8.

10. Ehrman JK, Gordon PM, Visich PS, Keteyian SJ (2018) Clinical exercise physiology. ( $4^{\text {th }}$ edn), Human Kinetics: Champaign, IL, USA.
Creative Commons Attribution 4.0 International License

For possible submissions Click Here

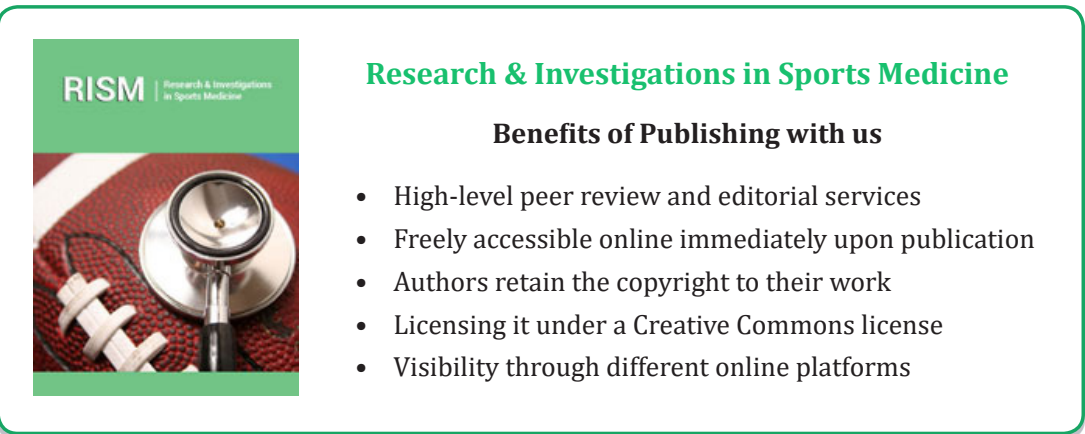

